\title{
Pandemia covid-19: perfil dos acometidos e protagonismo da tomografia computadorizada na pneumonia por SARS-COV-2
}

Pandemic covid-19: profile of the affected and protagonism of computed tomography in sars-cov-2 pneumonia
Pandemia covid-19: perfil del afectado y protagonismo de la tomografía computarizada en neumonía por sars-cov-2

\begin{abstract}
RESUMO
Objetivo: analisar o papel da tomografia computadorizada de tórax na avaliação do acometimento populacional por pneumonia durante a pandemia de COVID-19, em 2020. Método: Trata-se de um estudo retrospectivo onde foram analisados os laudos e imagens de 103 pacientes, internados no período de 01 a 30 de abril de 2020, com suspeita de pneumonia por COVID-19, Fortaleza, Ceará. Resultado: 0 quantitativo de pacientes que apresentaram imagens sugestivas para COVID-19 foi de $65 \%$ dos pacientes admitidos. A média geral de idade dos pacientes com tomografia positiva para infecção foi de 58,68 anos. Os principais achados descritos em laudos analisados foram: padrão de vidro fosco em $97,01 \%$ dos casos, consolidações parenquimatosas em $13,43 \%$, estrias em $29,85 \%$ e derrame pleural em $4,47 \%$ dos pacientes examinados. Conclusão: A tomografia computadorizada de tórax demonstra protagonismo como ferramenta diagnóstica e tem sido determinante para o isolamento e monitoramento de grande parcela dos pacientes infectados.
\end{abstract}

DESCRITORES: Pandemia; Tomografia Computadorizada; Tórax; Covid-19.

\begin{abstract}
Objective: this study aimed to analyze the role of thoracic computed tomography in the evaluation of the involvement of the population with pneumonia during the COVID-19 pandemic in 2020. Method: This is a retrospective study in which the reports and images of 103 patients hospitalized from April 1 to 30, 2020, with suspected COVID-19 pneumonia, in Fortaleza, Ceará, were analyzed. Result: The number of patients who presented images suggestive of COVID-19 was $65 \%$ of hospitalized patients. The overall mean number of patients with positive tomography for infection was 58.68 years. The main findings described in the analyzed reports were: ground glass pattern in $97.01 \%$ of the cases, parenchymic consolidations in $13.43 \%$, stretch marks in $29.85 \%$ and pleural effusion in $4.47 \%$ of the patients examined. Conclusion: Computed tomography of the chest is a highlight as a diagnostic tool and has been decisive for the isolation and follow-up of most infected patients.
\end{abstract}

DESCRIPTORS: Pandemic; Computed tomography; Thorax; Covid-19.

\section{RESUMEN}

Objetivo: Este estudio tuvo como objetivo analizar el papel de la tomografía computarizada del tórax en la evaluación de la afectación de la población por neumonía durante la pandemia de COVID-19 en 2020. Método: Se trata de un estudio retrospectivo en el que se analizaron los informes e imágenes de 103 pacientes hospitalizados del 1 al 30 de abril de 2020, con sospecha de neumonía por COVID-19, Fortaleza, Ceará. Resultado: El número de pacientes que presentaron imágenes sugestivas para COVID-19 fue del $65 \%$ de los pacientes ingresados. La edad media global de los pacientes con tomografía positiva para la infección fue de 58,68 años. Los principales hallazgos descritos en los informes analizados fueron: patrón de vidrio mate en el $97,01 \%$ de los casos, consolidaciones parenquimatosas en el $13,43 \%$, estrías en el $29,85 \%$ y derrame pleural en el $4,47 \%$ de los pacientes examinados. Conclusión: La tomografía computarizada del tórax demuestra protagonismo como herramienta diagnóstica y ha sido determinante para el aislamiento y seguimiento de una gran parte de los pacientes infectados.

DESCRIPTORES: Pandemia; Tomografía Computarizada; Tórax; Covid-19.

RECEBIDO EM: 17/05/2021 APROVADO EM: 30/08/2021 


\section{REGINA PAULA SOARES DIEGO}

Coordenadora técnica na Clínica Omnimagem e doutoranda no PPG Ciências Farmacêuticas da UFC. Mestre. Bacharel em Biomedicina

ORCID: 0000-0002-9606-0598

\section{LINDENBERG BARBOSA AGUIAR}

Médico radiologista. Clínica Omnimagem. Bacharel Medicina

ORCID: 0000-0002-9592-7006.

ISABELLE BERNARDINA DA SILVA LOPES

Biomédica Imagenologista na Clínica Omnigamem. Bacharel em Biomedicina

ORCID: 0000-0003-3329-524X.

\section{EVEANIA ARAÚJO COELHO DO NASCIMENTO}

Tecnóloga em Radiologia na Clínica Omnimagen. Especialista. Bacharel em tecnólogo em radiologia

ORCID: 0000-0003-1532-1280.

\section{JEFESSON RODRIGUES DE ALMEIDA}

Estudante no Unifanor-Wyden. Graduando em Biomedicina

ORCID: 0000-0002-2188-0057.

\section{GANDHI RÁDIS BAPTISTA}

Professor Associado da Universidade Federal do Ceará (UFC) e orientador do programa de pós-graduação em Ciências Farmacêuticas da UFC, Membro da Sociedade Americana de Química (American Chemical Society, ACS). Doutor. Bacharel em Farmácia Bioquímica.

ORCID: 0000-0001-9210-092X.

\section{INTRODUÇÃO}

E m dezembro de 2019, casos de pneumonia grave de causa desconhecida foram relatados em Wuhan, província de Hubei, China. Uma nova cepa de coronavírus pertencente à mesma família de vírus que causa a síndrome respiratória aguda grave (SARS) e a síndrome respiratória do Oriente Médio (MERS), bem como os 4 coronavírus humanos associados ao resfriado comum, foi subsequentemente isolada do trato respiratório inferior de 4 amostras de casos em 7 de janeiro de $2020^{1}$. A pandemia originada na província de Hubei, na China, estendeu-se a mais de 215 países ultrapassando, no final de abril de 2020, 3.25 milhóes de infectados e 230 mil óbitos. A infecção viral, síndrome respiratória aguda grave coronavírus 2 (SAR$\mathrm{S}-\mathrm{CoV}-2$ ), pode ser assintomática ou pode resultar em doença sintomática leve a grave (COVID-19) ${ }^{2}$, .

A Comissão Nacional de Saúde da República Popular da China, em fevereiro de 2020, lançou a $5^{a}$ edição do "Diagnóstico
A infecção
viral, síndrome

respiratória aguda grave coronavírus

2 (SARS-

CoV-2), pode ser

assintomática ou

pode resultar em

doença sintomática

leve a grave

(COVID-19) e plano de gestão da nova pneumonia ocasionada por coronavírus" e destacou o papel da Tomografia Computadorizada (TC) na província de Hubei para promover a detecção e o isolamento precoce. A TC pode desempenhar um papel mais importante no manejo de pacientes com COVID-19, desde o diagnóstico até o monitoramento qualitativo e quantitativo ${ }^{4}$.

As imagens de tórax foram empregadas no acompanhamento de pacientes demonstrando as evoluções dos quadros de pneumonia, fornecendo informações claras e dinâmicas acerca das lesões pulmonares, incluindo reconstruções multiplanares e tridimensionais volumétricas,${ }^{5}$. O exame pode ainda fornecer informações quantitativas, incluindo porcentagem de acometimento por lesões e valores de densidade média do parênquima pulmonar ${ }^{7,8}$.

Os achados típicos da pneumonia ocasionada por COVID-19 são inespecíficos, bem como para as demais infecções pulmonares, além de variar conforme o estágio clínico da enfermidade em cada indivíduo?. Portanto, o padrão encontrado nas imagens 
deve ser sempre correlacionado com os sintomas clínicos e resultados laboratoriais. $\mathrm{O}$ diagnóstico definitivo da doença deve ser confirmado através do teste RT-PCR ${ }^{9}{ }^{10}$.

As manifestações tomográficas da pneumonia por COVID-19, de modo geral, são apresentadas por uma lesão que se origina de um nódulo redondo no centro do lóbulo pulmonar secundário, que geralmente é mostrado como opacidade em vidro fosco redondo no início, posteriormente se estendendo a todos os lóbulos pulmonares secundários, formando imagens lobulares irregulares ${ }^{11},{ }^{10}$. A estimulação inflamatória leva ao espessamento dos vasos sanguíneos da lesão, o que resulta em alterações correspondentes visualizadas nas imagens ${ }^{10}$.

Estudos tem evidenciado um papel de protagonismo da tomografia computadorizada no diagnóstico precoce e acompanhamento do acometimento pulmonar por COVID-19 $9^{12}$. Através do que foi supracitado este estudo teve como objetivo analisar as principais características do acometimento populacional por pneumonia de etiologia viral Sars-Cov-2 durante a pandemia de COVID-19, na cidade de Fortaleza - Ceará, em 2020.

\section{MÉTOdOS}

O presente estudo se caracteriza como um levantamento descritivo e retrospectivo com abordagem quantitativa, uma vez que reúne dados sobre os resultados verificados em análise de imagens e laudos de exames Tomografia Computadorizada de Tórax de pacientes oriundos do serviço de emergência, os quais realizaram exames para o diagnóstico, o estadiamento e o monitoramento de resposta-tratamento de pneumonia ocasionada por COVID-19, no período de 01 a 30 de abril de 2020.

A amostra foi composta por imagens tomográficas de tórax de 103 pacientes. Para composição da amostra foram considerados os seguintes critérios de inclusão: imagens de pacientes de ambos os sexos e de qualquer idade, com suspeita de diagnóstico de pneumonia causada por COVID-19, encaminhados pelo centro de emergência anexo ao referido serviço de radiologia, portadores de solicitação médica para realização de tomografia computadorizada de tórax durante o mês de abril de 2020. Foram excluídas as imagens de pacientes que não obedeciam os critérios de inclusão previamente relatados.

A referida pesquisa foi realizada dentro do serviço de tomografia computadorizada da Clínica Omnimagem, situada na cidade de Fortaleza - Ceará. As imagens foram todas adquiridas sem a necessidade de administração de meios de contraste. Para este procedimento, utilizou-se equipamento de Tomografia Computadorizada Multislice Canon/Toshiba Modelo Alexion, 32 canais (TOSHIBA Medical do Brasil Ltda), devidamente calibrado e aprovado para uso clínico.

Análise de dados foi realizada mediante o emprego do software PADPRISM versão 5.0, onde as imagens adquiridas e os achados mais relevantes demonstrados nos laudos emitidos pelo serviço foram abordados utilizando recursos de estatística descritiva de natureza univariada, incluindo medidas de frequência. $\mathrm{O}$ instrumento utilizado para coleta de dados foi o banco de dados
Picture Archiving and Comunication System (Sistema PACS), através do qual recuperaremos as imagens dos pacientes admitidos sob caráter emergencial.

Para composição do referencial teórico deste trabalho, foi realizada busca por artigos publicados nos principais bancos $\mathrm{de} \mathrm{da}$ dos científicos (CAPES PERIÓDICOS, PUBMED, GOOGLE ACADÊMICO), entre os anos de 2020 e 2021, sob utilização das palavras chaves Tomografia Computadorizada, Tórax e COVID-19.

Foi solicitada dispensa de aplicação do Termo de Consentimento Livre e Esclarecido - TCLE por se tratar de uma pesquisa restropectiva baseada em imagens arquivadas em banco de dados da clínica cedente. O Projeto desta pesquisa foi submetido ao Comitê de Ética 5054 - UFC - Universidade Federal do Ceará / PROPESQ-UFC, via Plataforma Brasil, sob CAAE $n^{\circ}$ 51471221.5.0000.5054 e Protocolo $n^{\circ}$ 101954/2021. Durante todo processo de pesquisa, principalmente na fase de coleta de informações, foram respeitados todos os preceitos éticos estabelecidos na Resolução $n^{\circ} 466 / 12$ do CNS/MS/BRASIL.

\begin{tabular}{|c|c|c|}
\hline $\begin{array}{c}\text { ACHADOS DESCRITOS } \\
\text { EM LAUDO }\end{array}$ & $\begin{array}{c}\text { N}^{\circ} \\
\text { DE PACIENTES QUE } \\
\text { APRESENTARAM A } \\
\text { ALTERAÇÃO }\end{array}$ & $\begin{array}{l}\text { PACIENTES COM O } \\
\text { REFERIDO PADRÃO } \\
\text { DENTRE INDIVIIDUOS } \\
\text { INFECTADOS (\%) }\end{array}$ \\
\hline Padrão de Vidro Fosco & 65 & 97,01 \\
\hline $\begin{array}{l}\text { Consolidações } \\
\text { Parenquimatosas }\end{array}$ & 09 & 13,43 \\
\hline Presença de Estrias & 20 & 29,85 \\
\hline Derrame Pleural & 03 & 04,47 \\
\hline dos da pesquisa, 2021. & & \\
\hline
\end{tabular}




\section{artigo}

Diego, R. P. S, Aguiar, L. B., Lopes, I. B. D., Almeida, J. R., Baptista, G. R.

Pandemia covid-19: perfil dos acometidos e protagonismo da tomografia computadorizada na pneumonia por sars-cov-2

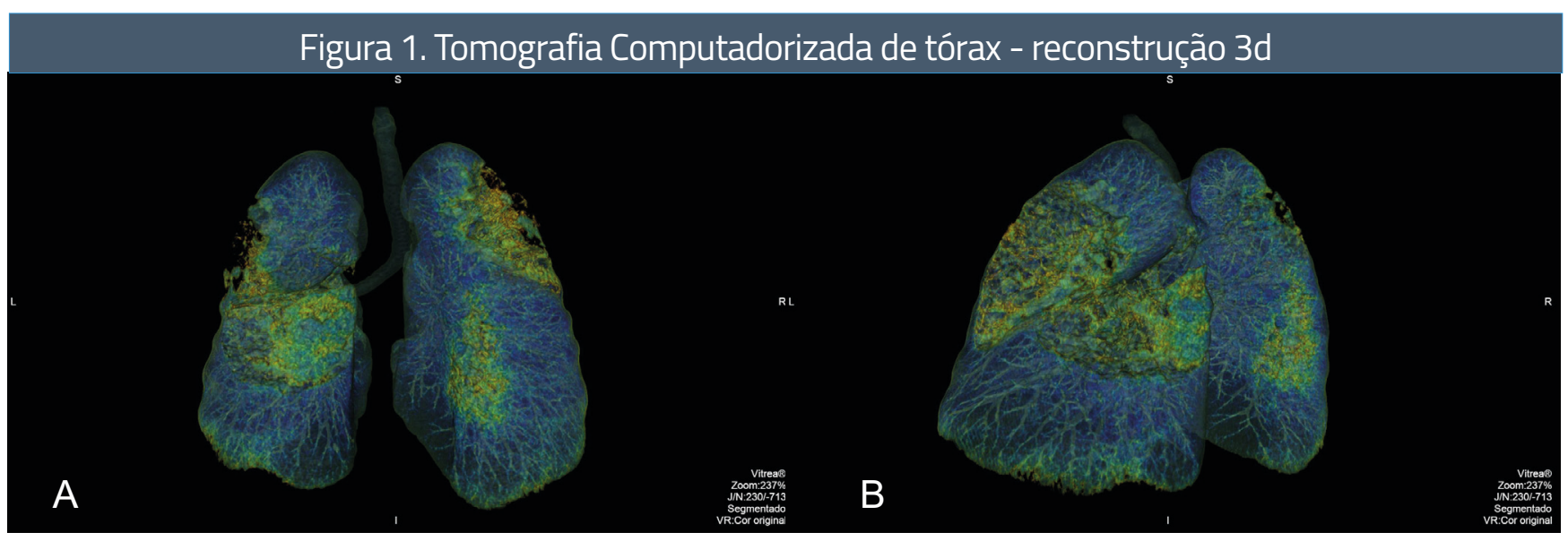

Fonte: Dados da pesquisa, 2020. (A e B) Exemplos de imagens de Tórax por Tomografia Computadorizada de pacientes suspeitos de infecção por COVID-19. Reconstrução Tridimensional demonstrando lesões parenquimatosas (áreas amarelas) de padrão predominantemente periférico (opacidades em padrão de vidro fosco) com acometimento bilateral dos pulmões.

\section{RESULTADOS}

Foram admitidos 103 pacientes, com média de idade de 55,87 anos, provenientes do serviço de emergência do Hospital Central de Fortaleza para realização de exame de tomografia computadorizada de tórax durante o mês de abril de 2020 (primeira onda da pandemia COVID-19), dentre os quais 57 eram homens, compreendendo $55,30 \%$ dos indivíduos examinados e 46 eram mulheres (44,70\%).

O quantitativo de pacientes que apresentaram imagens sugestivas para COVID-19 foi de 67 , correspondendo a $65 \%$ do total de pacientes admitidos durante o referido período. A média geral de idade dos pacien- tes com tomografia positiva para infecção foi de 58,68 anos e $58 \%$ dos pacientes com tomografia positiva para pneumonia eram homens (39).

Os principais achados descritos em laudo nas tomografias computadorizadas de tórax analisadas foram: Padrão de Vidro Fosco em 97,01\% dos casos, Consolidações Parenquimatosas em 13,43 \% exames, Estrias em 29,85\% e Derrame Pleural em $4,47 \%$ dos pacientes examinados (Tabela 1).

As lesões encontradas em parênquima pulmonar apresentaram padrão periférico em 53,73\% dos casos (36 pacientes), com acometimento bilateral dos pulmões em 56 exames, correspondendo a $83,58 \%$ de todos os casos positivos observados na to-

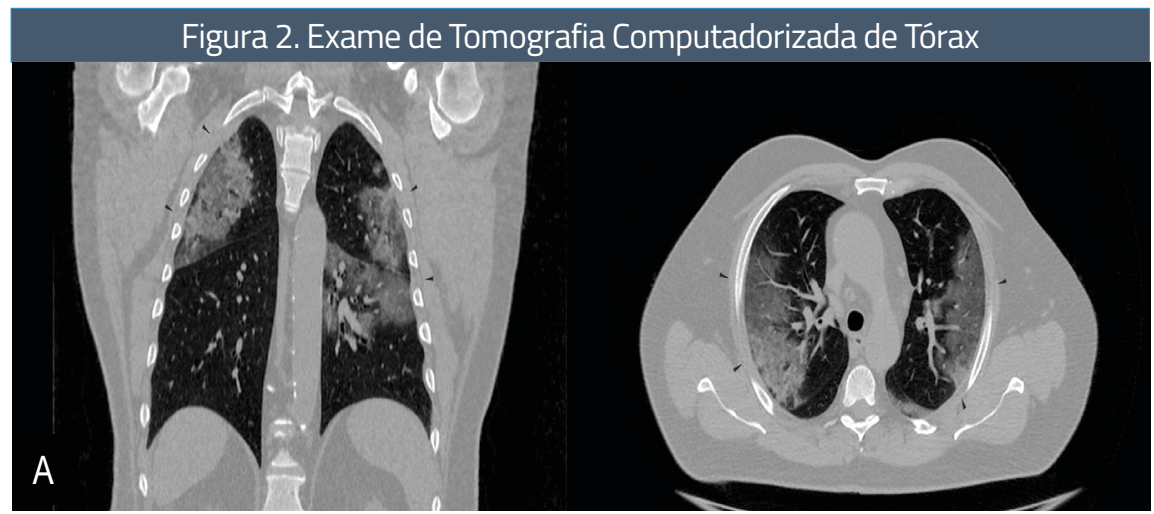

Fonte: Dados da pesquisa, 2020. Imagens de TC do Tórax em plano coronal (A) e axial (B) demonstrando opacidades em padrão de vidro fosco (setas) no parênquima pulmonar, bilateralmente. mografia computadorizada de tórax, como representado na Figura 1.

Em 88,05\% dos pacientes acometidos (59), observou-se comprometimento de lobos pulmonares inferiores enquanto que o envolvimento de lobos pulmonares superiores foi detectado em $64,17 \%$ dos pacientes positivos (43) para a infecção.

A observação de conteúdos esparsos em parênquima pulmonar foi descrita em 34 laudos de tomografia computadorizada de tórax positivas para pneumonia de provável etiologia viral $(50,74 \%)$.

\section{DISCUSSÃO}

Ainda que alguns achados possam se sobrepor aos padrões observados em outras infecções virais, algumas variações tomográficas referentes a COVID-19 têm características peculiares se comparadas àquelas vistas em outras infecções. Dentre os achados, o mais característico é o de múltiplas opacidades em vidro fosco de morfologia arredondada, com predomínio nas regiões periféricas dos lobos pulmonares e em regiões posteriores, frequentemente nas bases ${ }^{12}$.

O acometimento por COVID-19 é, na maioria das vezes, multilobar e bilateral. Em alguns casos pode evoluir para padrão de pavimentação em mosaico e apresentar consolidações no decorrer da infecção. $\mathrm{O}$ padrão vidro fosco não é totalmente específico para infecção viral, podendo ser evi- 
denciado em infecções de outras etiologias ou ainda não possuir origem infecciosa ${ }^{12},{ }^{13}$.

Na COVID-19, este achado é comumente encontrado nos primeiros dias dos sintomas. Em pacientes com quadros clínicos mais graves, normalmente evidencia-se a presença de derrame pleural, sugerindo pior prognóstico ${ }^{13}$, . Seguido da opacidade em vidro fosco, a consolidação é a segunda alteração mais comumente encontrada na pneumonia causada pela COVID-19, estabelecendo-se em fases mais tardias da infecção, entretanto, ambas alterações podem manifestar-se concomitantemente. As consolidações são representadas pelo preenchimento dos alvéolos pulmonares por exsudato inflamatório caracterizando aumento da densidade pulmonar, com obscurecimento de vasos sanguíneos e seus interstícios ${ }^{7},{ }^{12}$, .

Aspectos semelhantes nas tomografias computadorizadas foram relatados, com predomínio de lesões vesiculares, geralmente com envolvimento bilateral e multifocal, distribuição periférica e predominância em regiões pulmonares médio-inferiores e posteriores $^{13}$. Também foram descritos espessamentos septais e lesões reticulares sobrepostas a lesões alveolares que refletem o envolvimento intersticial concomitante, especialmente em pacientes em estágio mais avançado da doença. Lesões cicatriciais iniciais nos pulmões (estrias fibróticas) e derrame pleural também estão presentes em estágios mais avançados da patologia ${ }^{7},{ }^{8},{ }^{14}$.

Dentre todos os pacientes submetidos ao exame, a maioria teve confirmação de pneumonia de provável etiologia viral (65\% dos pacientes) e a idade média destes pacientes foi de 58,68 anos, índice um pouco abaixo da idade apontada pela literatura como população alvo para a etiologia (público a partir de 60 anos). A predominância do sexo masculino demonstra que os homens tendem a ser mais propensos a desenvolver a doença, pois de acordo com So$\operatorname{ares}^{15}$, isso pode estar interligado ao estilo de vida não saudável, associados pelo fumo e alcoolismo, além do negligenciamento do isolamento social e práticas preventivas.

$\mathrm{O}$ padrão de vidro fosco foi observado em $97,0 \%$ das imagens de tomografia com-

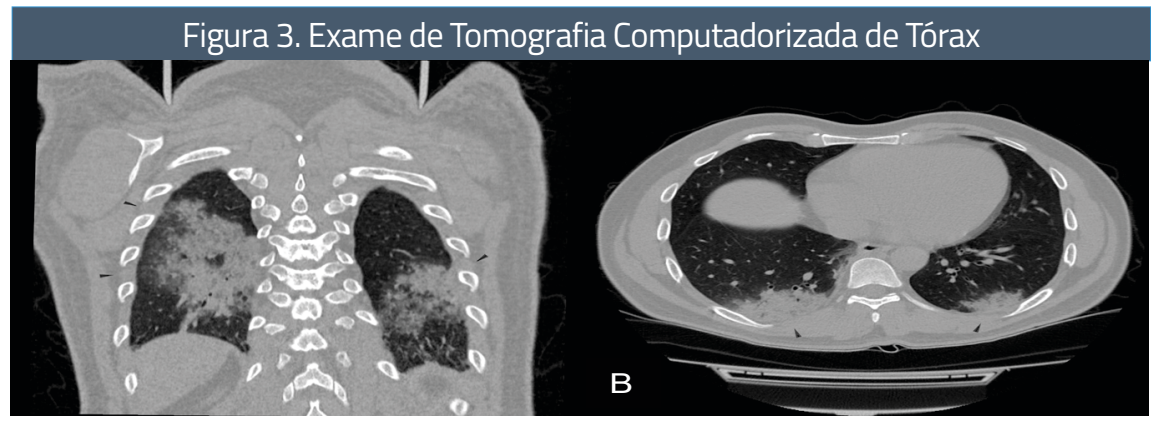

Fonte: Dados da pesquisa, 2020. Imagens de TC de Alta Resolução do Tórax em plano coronal (A) e axial (B) evidenciando consolidações parenquimatosas (setas), em região pulmonar posterior, bilateralmente.

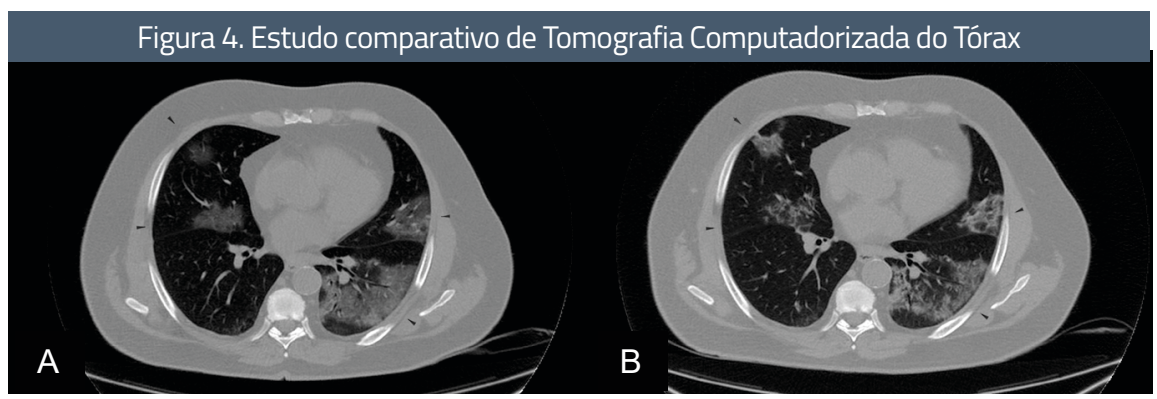

Fonte: Dados da pesquisa, 2020. Imagens de TC do Tórax em plano axial (paciente do sexo masculino com 65 anos) adquiridas nos dias 09/04/2021 (A) e 15/04/2021 (B) demonstrando melhora do quadro de pneumonia de etiologia viral mediante evidências de regressão das lesões (setas).

putadorizada de tórax positivas (Figura 2), enquanto que consolidações parenquimatosas foram relatadas em apenas 13,43\% dos casos e derrame pleural em 4,47\% destes exames (Figura 3). Estes achados demonstram a grande sensibilidade da tomografia computadorizada na detecção precoce da doença, evidenciando alterações em quadros iniciais de pneumonia ocasionada por SARS-CoV-2.

A tomografia computadorizada tem permitido, através da correlação de imagens de tórax adquiridas em periodicidade, o monitoramento de pacientes e a verificação da evolução do quadro clínico e resposta-tratamento (Figura 4).

\section{CONCLUSÃO}

Embora o diagnóstico da COVID-19 tem seu confirmatório somente por meio do teste RT-PCR, a tomografia computadorizada de tórax demonstra protagonismo como ferramenta diagnóstica disponível e tem sido determinante para o isolamento e monitoramento de grande parcela dos pacientes infectados. Em conjunto com os achados radiológicos, compreender o perfil populacional dos acometidos por Sars-Cov-2 tem demonstrado sua importância no âmbito da saúde coletiva e epidemiológica, pois a prevalência dos acometidos pelo vírus tende a se alterar ao decorrer de suas mutações.

É de fundamental importância que as equipes envolvidas no atendimento a pacientes em centros de radiodiagnóstico reconheçam os achados radiológicos sugestivos de pneumonia viral compatíveis com a COVID-19, contribuindo desta forma para o isolamento dos indivíduos acometidos pela patologia e consequentemente colaborem para contenção da disseminação do SARS-CoV- 2. . 


\section{REFERÊNCIAS}

1. Lauer SA, Grantz KH, Bi Q, Jones FK, Zheng Q, Meredith HR et al. The Incubation Period of Coronavirus Disease 2019. Ann Intern Med 2020;172(9):577-582. DOI: 10.7326/M20-0504.

2. Wu Z, McGoogan JM. Characteristics of and important lessons from the coronavirus disease 2019 (COVID 19) outbreak in china: summary of a report of 72314 cases from the chinese center for disease control and prevention. JAMA. 2020;323(13): 12391242. DOI:10.1001/jama.2020.2648

3. Xu Z, Shi L, Wang Y, et al. Pathological findings of COVID 19 associated with acute respiratory distress syndrome. Lancet Respir Med. 2020;8(4): 420 422. DOI: 10.1016/S22132600(20)30076-X.

4. QI, Xiaolong, Junqiang $L$, Qian Y, et al. CT imaging of coronavirus disease 2019 (COVID-19): from the qualitative to quantitative. Annals of translational medicine, vol. 8,5 2020;256. DOI: 10.21037/atm.2020.02.91

5. Fauci AS, Lane HC, redfield RR. Covid-19 - Navigating the Uncharted. N Engl J Med. 2020; 382:1268-1269 . DOI: 10.1056/ NEJMe2002387

6. Qin C, Liu F, Yen TC, et al.18F-FDG PET/CT findings of COVID-19: a series of four highly suspected cases. Eur J Nucl Med Mol Imaging, 2020;47(5):1281-1286. DOI: 10.1007/s00259-02004734-w

7. Romano L, Pinto A, Merola S, et al. Intensive-care unit lung infections: The role of imaging with special emphasis on multi-detector row computed tomography. Eur J Radiol, 2008;65(3):3339. DOI: 10.1016/j.ejrad.2007.09.018

8. Zu ZY, Jiang MD, Xu PP, et al. Coronavirus Disease 2019 (COVID-19): A Perspective of China. Radiology, 2020: 200-490. Disponível em: https://doi.org/10.1148/radiol.2020200490
9. Kanne JP, Little BP, Chung JH, et al. Essentials for Radiologists on COVID-19: An Update-Radiology Scientific Expert Panel. Radiology. 2020; 200-527. Disponível em: https:/doi.org/10.1148/ radiol.2020200527

10. Araújo-Filho JAB, Sawamura MVY, Costa AN, et al. Pneumonia por COVID-19: qual o papel da imagem no diagnóstico?. J Bras Pneumol, 2020;46(2):2020-0114. Disponivel em: https:// dx.doi.org/10.36416/1806-3756/e20200114

11. Meng $H$, Xiong $R$, He $R$, et al. CT imaging and clinical course of asymptomatic cases with COVID-19 pneumonia at admission in Wuhan, China. The Journal of infection, 2020;81(1), 33-39. DOI: 10.1016/j.jinf.2020.04.004

12. Rosa MEE, Matos MJR, Renata Furtado SOP, Brito VM, Maral, LTW, Beraldo GL, et al. Achados da COVID-19 identificados na tomografia computadorizada de tórax: ensaio pictórico. Einstein, 2020;18. DOI: 10.31744/einstein_journal/2020RW5741

13. Song F, Shin N, Shan F, et al. Emergindo 2019 Novel Coronavirus (2019-nCoV) Pneumonia. Radiology, 2020:200-274. Vol. 295, No. 1. Disponivel em: https://doi.org/10.1148/radiol.2020200274

14. Zhou S, Wang Y, Zhu T, et al. CT Features of Coronavirus Disease 2019 (COVID-19) Pneumonia in 62 Pacientes em Wuhan, China. AJR Am J Roentgenol. 2020; 214(6):1287-1294. DOl: 10.2214/AJR.20.22975

15. Soares, AJ, Soares, CFS, Santos Silva, FC, Ferreira da Silva, $A_{1 ;}$ Estrela, FM, Magalhães, JRF, et al. Elementos da masculinidade que vulnerabilizam homens à morbimortalidade pela COVID-19: revisão integrativa. Saúde Coletiva, 2021: 11 (N)65. DOI: https:// doi.org/10.36489/saudecoletiva.2021v11i65p5926-5939 